\title{
A Comparative Experimental Study on Fault Diagnosis of Rolling Element Bearing Using Acoustic Emission and Soft Computing Techniques
}

\author{
C. Ratnama, N.M. Jasmina, V.V. Rao ${ }^{b}$, K.V. Rao ${ }^{c}$ \\ aMechanical Engineering Department, A.U College of Engineering (A), Visakhapatnam, India, \\ ${ }^{\mathrm{b}}$ AGM, Shops \& Foundry Dept., Visakhapatnam Steel Plant, Visakhapatnam, India, \\ ' Mechanical Engineering Department, Vignan's Foundation for Science, Technology and Research, A.P., India.
}

Keywords:

\section{Diagnosis}

Rolling Element Bearings

Artificial Neural Network

Support Vector Machine

\section{Corresponding author:}

Nerella Mary Jasmin

Department of Mechanical

Engineering,

A.U. College of Engineering (A),

Visakhapatnam, A.P, India.

E-mail: jasminmary2@gmail.com

\begin{abstract}
A B S T R A C T
In engineering processes, Health condition Monitoring (HCM) is a faultfinding task to guarantee consistency of rotating machinery. Rolling Element Bearings (REBs) are the main origin of damage in such equipment. They are the key components used in most of the rotating devices. These faults are mainly caused due to premature failure or improper installation of the machine element. Finding and analysis of defects is very vital in rotating machinery for its optimality. A test-rig was established to analyze the various line defects in REBs under different speeds and load conditions. The Acoustic Emission (AE) signatures responses are obtained and analyzed. Soft computing methods, especially Artificial Neural Network (ANN) and Support Vector Machine (SVM) used to compare with experimental results for fault diagnosis of bearings. The $A E$ statistical features were fed as inputs in ANN and SVM. A comparative experimental study on prediction of seeded defect size is carried out using soft computing methods. This study concludes that these methods can be used for prediction of rolling element bearings seeded faults.
\end{abstract}

(C) 2018 Published by Faculty of Engineering

\section{INTRODUCTION}

In Engineering and Manufacturing industries, such as aeronautical, automation, power generation and plants application the Health Condition Monitoring (HCM) is a fault-finding task to guarantee consistency of rotating machinery. Due to their reliability and the origin of the faults in bearings are the key elements in rotating machinery. Prediction of such type of faults and their sizes using vibration and acoustic emissions (AEs) signals had been reported [1-4]. To overcome the drawback of Vibration based techniques for the rolling element bearing condition monitoring to detect incipient defects in the bearing. Acoustic emission (AE) is introduced as a complementary method for condition monitoring of bearings as $\mathrm{AE}$ is very sensitive to initial defects [5]. Detection of faults in bearing condition monitoring of machines running in health and unhealthy conditions acoustic emission signals 
used. The same signals also be used to trace the incipient catastrophes of the machine elements. Some of the works in this area are listed in [613]. In this paper, a new strategy based on the fusion of different Support Vector Machines (SVM) is proposed to reduce noise effect in bearing fault diagnosis systems. Each SVM classifier is designed to deal with a specific noise configuration and, when combined - by means of the Iterative Boolean Combination (IBC) technique - they provide high robustness to different noise-to-signal ratio. To produce a high amount of vibration signals, considering different defect dimensions and noise levels, the BEA ring Toolbox (BEAT) is employed in this work. Experiments indicate that the proposed strategy can significantly retain the presence of, even in the presence of very noisy signals [14]. Study of Acoustic emission as an emerging technique for condition monitoring of rolling element bearings as well as potentially offers advantages for detection of incipient damage at an early stage of failure [15]. Cyclostationary tools applied to the acoustic emission to detect a very small defect of 40 microns compared with the vibration measurement. The cyclic spectral density (CSD) is computed for all acoustic emission and vibration signals and the results show that the acoustic emission measurement is more efficient than the vibration measurement for an early detection of degradation even when defect is very small with increasing the speed [16]. Compared between vibration and AE signal monitoring as a tool for induction motor bearing fault detection. Statistical parameters used in time-domain includes RMS, crest factor, and kurtosis whereas for frequency-domain, normal spectrum and envelope spectrum using Hilbert transform were applied. The results reveal that vibration and $\mathrm{AE}$ signals are effective measurement to detect bearing faults in both time- and frequency-domain. Visual inspection of acceleration and $\mathrm{AE}$ signal waveform, statistical analysis and envelope spectrum monitoring are the acceptable methods in detecting bearing fault [17]. Describes a filter that is designed to track shocks in the time domain, and to isolate them from any other random or harmonic components. This innovative tool can be used in the time domain as a denoising filter to estimate the proportion of the total signal energy caused by the shocks and to quantify the severity of damage. It can also be applied in the frequency domain and will allow through envelope or time-frequency analysis to clearly identify the sources of the shocks even if they are from various origins. And help to diagnose the severity of damage even with multiple defects [18]. In this study, Empirical Mode Decomposition (EMD) is one of the techniques for an early detection of defects in many mechanical applications like bearings and gears. The EMD methodology decomposes the original time series data into intrinsic mode functions (IMF), by using the Hilbert-Huang transform. EMD applies to acoustic emission signals. The acoustic emission signal is heterodyned around a central high frequency to obtain an audible signal. Scalar statistical parameters such as Kurtosis and THIKAT are used in this study. These statistical descriptors are calculated for each IMF. It is found that the application of time descriptors of different IMF decomposition levels gives good results for early detection of defects in comparison with the original time signal [19].

\section{COMPUTATIONAL INTELLIGENCE METHODS}

\subsection{Artificial Neural Network}

Artificial neural networks (ANN) are interconnected group of nodes as a network of neurons in a brain also called as connectionist system or parallel distributed processing system and [20]. Cutting forces, quality of surface, tool life, tool wear, tool vibration etc., were predicted by ANN [21]. Show the construction of network that refers to a directed graph consisting of a set of nodes and set of connections between nodes. Each connection between two nodes is called Connection strength or weight. Vector $x$ represents inputs and a vector $\omega$ represents the connection strength efficiencies. Therefore, the neuron output magnitude can get from the formula shown in [22].

$$
y=f\left(\sum_{i} \omega_{i} x_{i}\right)=f(\omega \cdot x)=f\left(\omega^{T} x\right)
$$

Predicted temperature and tool wear accurately using ANN model [23]. Output values influence the vibrations through inputs using an ANN approach [24]. A supervised learning process also known as backpropagation is important in ANN and used in various applications like approximation, classification, and prediction or 
forecasting [22]. ANN as a classifier tested and trained using extracted features from vibration signals for rolling element bearings [25]. Rao et al. used ANN back-propagation algorithm, with input parameters of rms velocity, Load, vibration Revolutions Per Minute and seeded defect size as output. The ANN was trained and tested with data and predicted the defect size by conducing test runs [26]. Presents the design and development of artificial neural network-based model for the fault detection of REBs using a back propagation learning algorithm and multilayer perception neural network. Feature vector which is one of the most significant parameters to design an appropriate neural network were extracted from analysis of acoustic signals in time domain and frequency domain methods. The statistical features of acoustic signals such as $\mathrm{AE}$ amplitude ( $\mathrm{dB}$ level), RMS, Peak value, Crest factor, skewness, Kurtosis, Clearance Factor along with RPM, load was used an input to ANN. The predicted defect sizes are compared with the actual seeded defect sizes and the percentage error was minimal [27].

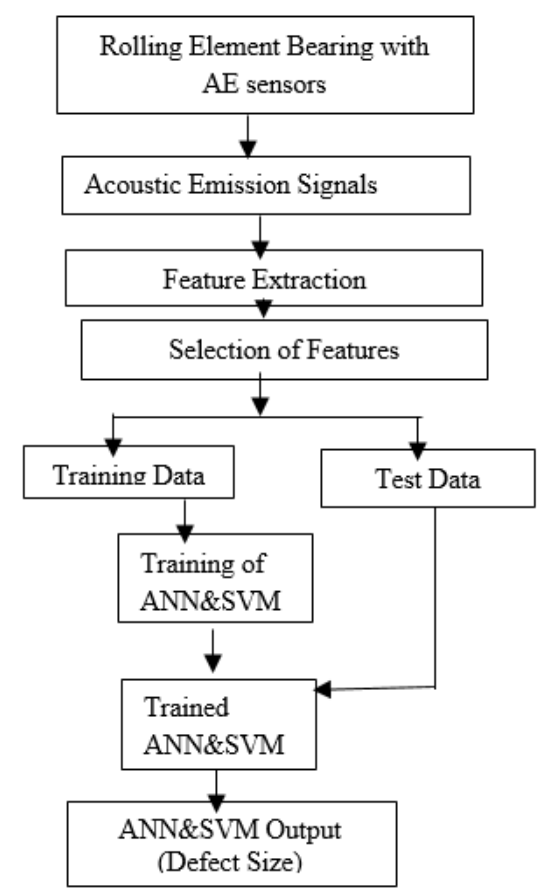

Fig. 1. Flow chart of bearing fault diagnosis.

\subsection{Support Vector Machine}

Support Vector Machine (SVM) was an excellent soft computing technique tool based on statistical learning theory introduced by Vladimir Vapnik [28] for good generalization. Large data are required in ANN to predict responses accurately where as in the SVM, less data is required with less error [29]. SVM is a part of supervised learning, demonstrated capability in classification and decision-making. Support Vector Machine (SVM) was an excellent soft computing technique tool based on statistical learning theory introduced by SVM is a part of supervised learning, demonstrated capability in classification and decision-making. $\left\{\left(x_{i}, y_{i}\right)\right\}_{i=1}^{N} \in$ $R^{m} X R$ where $x_{i}$-input vector, $y_{i}$ output value, $N$ training data. SVM model was used to estimate the defect size with less experimental data. Conventional empirical risk minimization principle overcomes by Structure risk minimization (SRM) principle is the main benefit of SVM. The linear function is formulated in the high dimensional feature space, with the form of a function given below [30].

$y=f(x)=\sum_{i=1}^{N} w_{i} \emptyset_{i}(x)+b=w^{T} \varnothing(x)+b$

where, $\varnothing(x)$ - high dimensional feature space nonlinearly mapped from the input space $x$. The weight vector $w=[w 1, w 2 \ldots . w N], \varnothing=\left[\varnothing_{1}, \phi_{2}, \ldots ..\right]$ and bias $b$ was estimated by minimizing.

$$
R(c)=C \frac{1}{n} \sum_{i=1}^{n} L\left(d_{i}, y_{i}\right)+\frac{1}{2}\left\|\omega^{2}\right\|
$$

Where,

$$
\begin{aligned}
L_{\epsilon}(d, y) & =\{|d-y|-\varepsilon,|d-y(x)| \geq \varepsilon\} \\
& =\{0, \quad \text { otherwise }\}
\end{aligned}
$$

$\mathrm{L}(\mathrm{d}, \mathrm{y})$ is the $\varepsilon$-intensive loss function. This mainly indicates that errors below $\varepsilon$ are not penalized. $\frac{1}{2} \omega^{2}$ measures the smoothness of the function. The term $\mathrm{C} \frac{1}{\mathrm{n}} \sum_{\mathrm{i}-1}^{\mathrm{n}} \mathrm{L}\left(\mathrm{d}_{\mathrm{i}}, \mathrm{y}_{\mathrm{i}}\right)$ is the empirical error. Both $C$ and $\varepsilon$ are prescribed parameters, $\varepsilon$ is called the tube size of SVM, and $\mathrm{C}$ is the regularization constant determining the trade-off between the empirical error and the regularized term.

For the detection of the bearing fault, consider scratch as a factor for fault analysis and the Fast Fourier Transform used. The bearing fault detection was performed with Support Vector Machine [31]. To improve the diagnosis of normal bearing, outer race fault inner race fault, and conditions and its accuracy the parameter evaluation technique is used to select five features that are used as predictors in multiclass support vector machine (SVM) classification [32]. Healthy and faulty valve conditions of compressor diagnosed by AE signal 
data. And estimation of fault by SVM based on training and testing samples [33]. Training and testing of SVM using the statistical time-domain features, extracted from a sample as a single observation [34]. Collect vibration signals from good and faulty conditions of the gearbox. With two different speeds and loading conditions each gear is tested. Extracted statistical features from the vibration signals. The extracted features are given as an input to the SVM for fault detection [35]. The technique is proposed for identifying faults in the rolling element bearings, based on an intelligent classifier technique called support vector machine (SVM). The proposed technique focuses on outer race faults experienced by the rotating machinery. Experiments are conducted on the defective bearing at different levels of speed and load conditions and acoustic emission (AE) data is collected for analysis. The SVM is trained with the experimental data to identify outer race faults using Acoustic emission signals collected in real-time by a data acquisition system. Results showed that the proposed SVM-based method was effective in identifying different outer race faults in the Rolling element bearings [36]. To predict tool breakage which is used in the face milling process by using cutting force data. This data was used to train the SVM model to predict tool breakage [37]. With and without optimized GA, the classifiers ANN and SVM had been analyzed for detecting gear condition using time-domain vibration signals with different load conditions [38]. Bearing fault detection by using ANNs and SVMs also called as machine learning techniques. Using statistical techniques features are extracted from time-domain vibration signals. Various speeds and with or without loads the role of time-domain vibration signals were examined. Classifier SVM showed better results than ANN [39]. Feature extraction, diagnosis through extracted features are two important parts in condition monitoring systems. Daubechies wavelet was introduced for minimizing the framework noise from vibration signal to smoothen the signals. Time domains features of vibration signals such as Peak difference, Kurtosis, Crest factor and RMS, are extracted. Neural network with Back propagation, Support vector machine were used to detect bearing faults. Here Support vector machine method shows best performance over ANN [40]. Time domain vibration signals were divided into 40 segments and statistical features such as std deviation, kurtosis, skewness etc. were extracted. SVM classifier and its effectiveness were compared with ANN classifier and found that SVM is superior to that of ANN. Also studied the effect of prepossessing of the vibration signal by Discreet Wavelet Transform (DWT) which enhances the effectiveness of both ANN and SVM classifiers [41]. ANN and SVM classifiers are studied and compared for condition monitoring of REB based on vibration data has been presented in this paper. Various dimensional and non-dimensional statistical features of the nonoverlapping segments of the time-domain vibration signal have been extracted. A separate index (SI) has been used to select the predominantly sensitive features [42]. Here both fault and fault free rotors were used to see the efficiency of statistical features for fault diagnosis. ANN and SVM methods had been used in rotating mechanical system. The vibration data and its features fed as input for training and testing ANN and SVM. The machine learning algorithms were used for reliable and fast diagnosis of rotor faults [43].

The experimental investigation reported was focused on prediction of seeded fault using methods ANN and SVM. For acoustic emission data acquisition, an MHC-Memo Pro (manufactured by Holroyd) AE instrument with a magnetic mount sensor of model 1030 Mag was used. The $\mathrm{AE}$ sensor was resonant piezoelectric at $100 \mathrm{kHz}$ frequency $24 \mathrm{~dB}$ gain. The AE time response signal data were processed through FFT with respect to $\mathrm{AE}$ lab software. Healthy bearing and bearing with various faults were considered for all test runs to analyze the time waves and frequency spectrums. Line defects in outer race were inspected. The obtained signals were processed for diagnosis as in the chart shown in Fig1. Extracted Features from the time domain signal by statistical technique. Features selected were used for training and testing of ANN and SVM with the known output. Finally, compare ANN and SVM resultant defect size with seeded defect size.

\section{EXPERIMENTAL SETUP AND DATA ACQUISITION}

Experimental setup shown in fig. 3 used to carry tests on the present work. Mounting and running the defective bearing in the test rig along with acquisition of $\mathrm{AE}$ data under different 
speed and load conditions. Test rig mainly consists of a shaft driven by a different speed range up to $2800 \mathrm{RPM}$ with a $16 \mathrm{kN}$ load capacity load was applied in hydraulic way. On the right side with the test bearings and on the left side the shaft is assembled by V-pulley. And the shaft is supported on both sides by two concealed deep groove ball bearings with plumber blocks. The $2.2 \mathrm{~kW}$ Motor placed on a separate base frame to free from vibrations to the test rig and the motor drives the shaft with the V-belt. The test bearing housing is square split housing which is made up of EN 24 steel material. On the top of the split housing $\mathrm{AE}$ probe and hydraulic loading ram are placed while observing the test run. A schematic diagram of the REBs for experimental validation is in Fig. 2, experiments were carried out to evaluate the proposed model for different speeds. The Bearing parameters are tabulated in Table 1. N312 bearing is a test Roller bearing where it has an option of outer race can be separated shown in Figs. 4 and 5. This bearing has an advantage of easy assemblage and dissembling of the outer race. Inside of the outer race surface, $0.3,0.5,0.7,0.9$ and $1.1 \mathrm{~mm}$ width defects respectively, are created with Wire Cut EDM (Electro Discharge Machining).

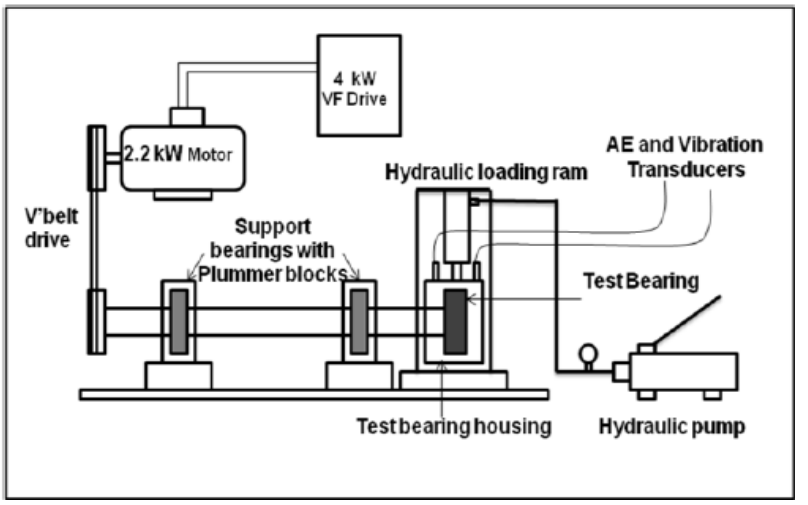

Fig. 2. Schematic layout of test rig.

A technique called acoustic emission method which has high signal to noise ratio is considered in bearing defect diagnosis than the vibration analysis. AE probe with MHC-Pro Acoustic Emission instrument was used for acquisition of vibration data, Test rig (Fig. 3) was used to conduct test runs from where the consistency of the data acquired was tested. First, conduct Test run-1 on healthy bearing. Next, conduct Test run- 2 on defect seeded outer race bearing. Both the Test runs conducted at various loading conditions and at different rpm's.

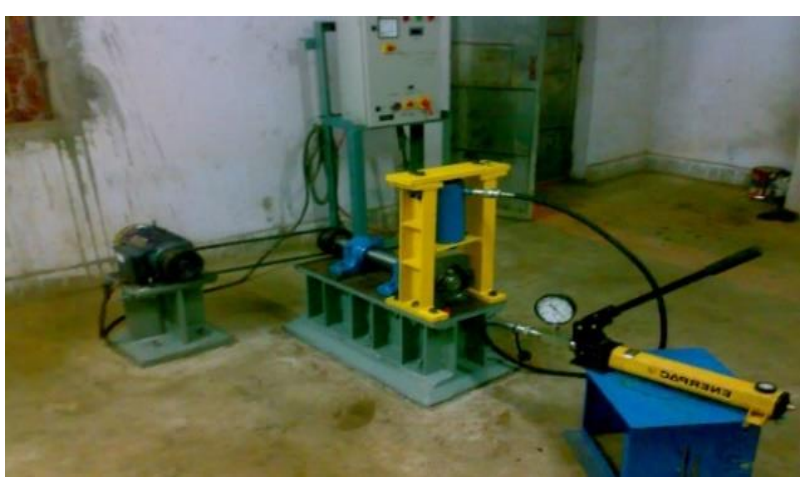

Fig 3. Test Rig.

Table 1. Test bearing specifications.

\begin{tabular}{|l|l|}
\hline Model No. & NTN N312 \\
\hline Rolling element dia $(\mathrm{d})$ & $18 \mathrm{~mm}$ \\
\hline Angle in contact $(\alpha)$ & $0^{0}$ \\
\hline Width $(w)$ & $31 \mathrm{~mm}$ \\
\hline Pitch circle dia $(\mathrm{Dp})$ & $96 \mathrm{~mm}$ \\
\hline No. of rollers & 12 \\
\hline Speed Range & $10-3000 \mathrm{rpm}$ \\
\hline Outer diameter & $130 \mathrm{~mm}$ \\
\hline Inner diameter & $60 \mathrm{~mm}$ \\
\hline Mass & $1.80 \mathrm{Kg}$ \\
\hline Max load & $16 \mathrm{kN}$ \\
\hline
\end{tabular}

Acoustic emission signal data are recorded, and post processed through AE lab software. AE data were collected. First, the time versus Amplitude data of bearing on its running condition were collected. For acoustic emission (AE) data acquired from MHC-memo pro (Holroyd make) $\mathrm{AE}$ instrument with a magnetic mount sensor of model 1030 Mag and 2048 samples (data points) are recorded per size for each time wave. The $\mathrm{AE}$ sensor is a resonant piezoelectric at $100 \mathrm{kHz}$ frequency $24 \mathrm{~dB}$ gain. This instrument recorded the time wave of 2048 samples of data per second to enable a repetition frequency spectrum to be calculated. Each AE envelope spectrum covers the frequency range of $0 \mathrm{~Hz}$ to $1000 \mathrm{~Hz}$ and in the representative of a one second period. A defect free bearing is assembled in the test bearing house and the test rig was run for minor adjustments. After that, the defect seeded bearing was assembled in the test bearing house and the defect was positioned at the top where the load was applied radially through hydraulic ram. Test runs are conducted at five speeds as N1=500, N2 $=700, N 3=900$, $\mathrm{N} 4=1100, \mathrm{~N} 5=1500$ and at two loads as $\mathrm{L} 1=4 \mathrm{kN}$ and $\mathrm{L} 2=2 \mathrm{kN}$ in six steps. Frequencies produced by the different defects of the rolling element bearing mainly depend on no. of rolling elements, bearing geometry, and shaft speed shown in Fig 6. 


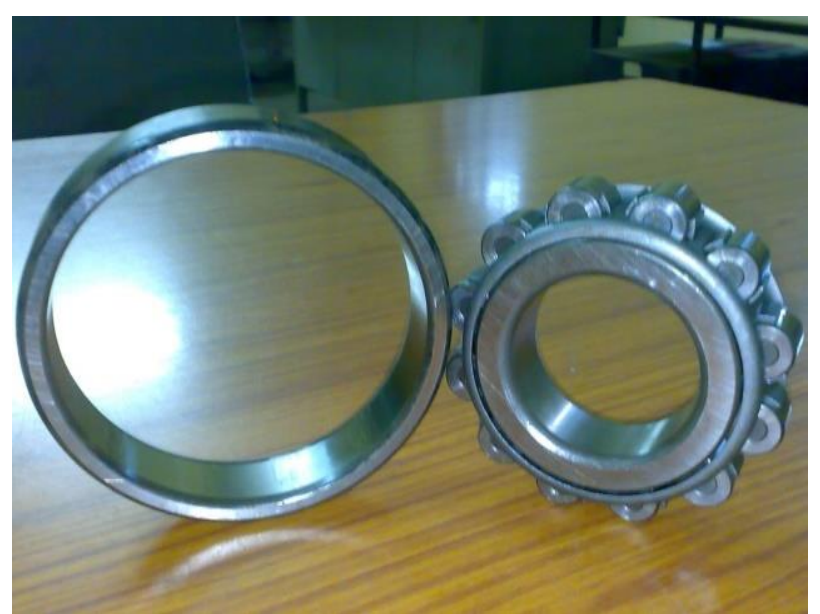

Fig. 4. Test Bearing.

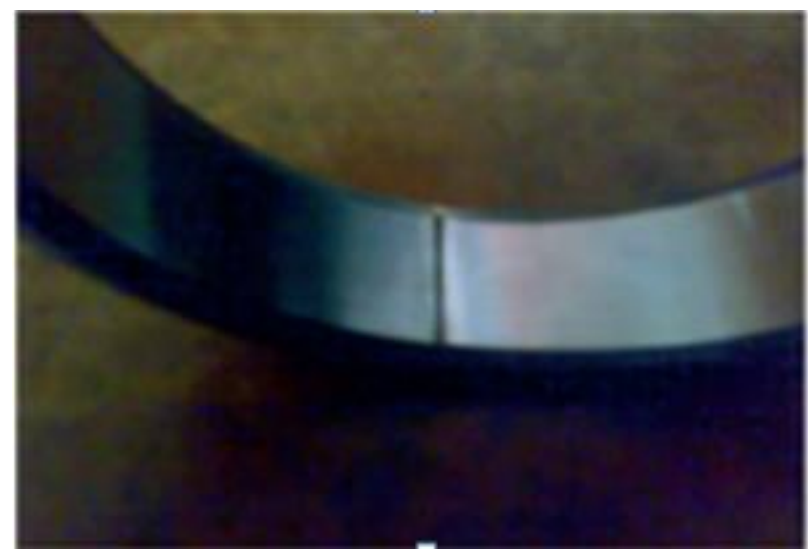

Fig. 5. Outer race seeded line defect.

Frequencies are stated in Eqs:

$$
\begin{array}{r}
F T F=\frac{1}{2}\left(f_{i}\right)\left(1-\frac{d \cos \theta}{D_{p}}\right) \\
B P F O=\frac{N}{2}\left(f_{i}\right)\left(1-\frac{d \cos \theta}{D_{p}}\right) \\
B P F I=\frac{N}{2}\left(f_{i}\right)\left(1+\frac{d \cos \theta}{D_{p}}\right) \\
\mathrm{BSF}=\frac{\mathrm{D}_{\mathrm{p}}}{2 \mathrm{~d}}\left(f_{i}\right)\left(1-\left(\frac{\mathrm{d} \cos \theta}{\mathrm{D}_{\mathrm{p}}}\right)^{2}\right)
\end{array}
$$

where,

FTF $=$ Cage Frequency,

BPFO = Characteristic Frequency of an Outer race fault,

BPFI = Characteristic Frequency of the Inner race fault,

BSF $=$ Roller Spin Frequency,

$\mathrm{Dp}=$ Pitch dia,

$f_{i}=$ Rotation frequency of inner race,

$\mathrm{N}=$ No. of rolling elements,

$\mathrm{d}=$ dia of rolling element.
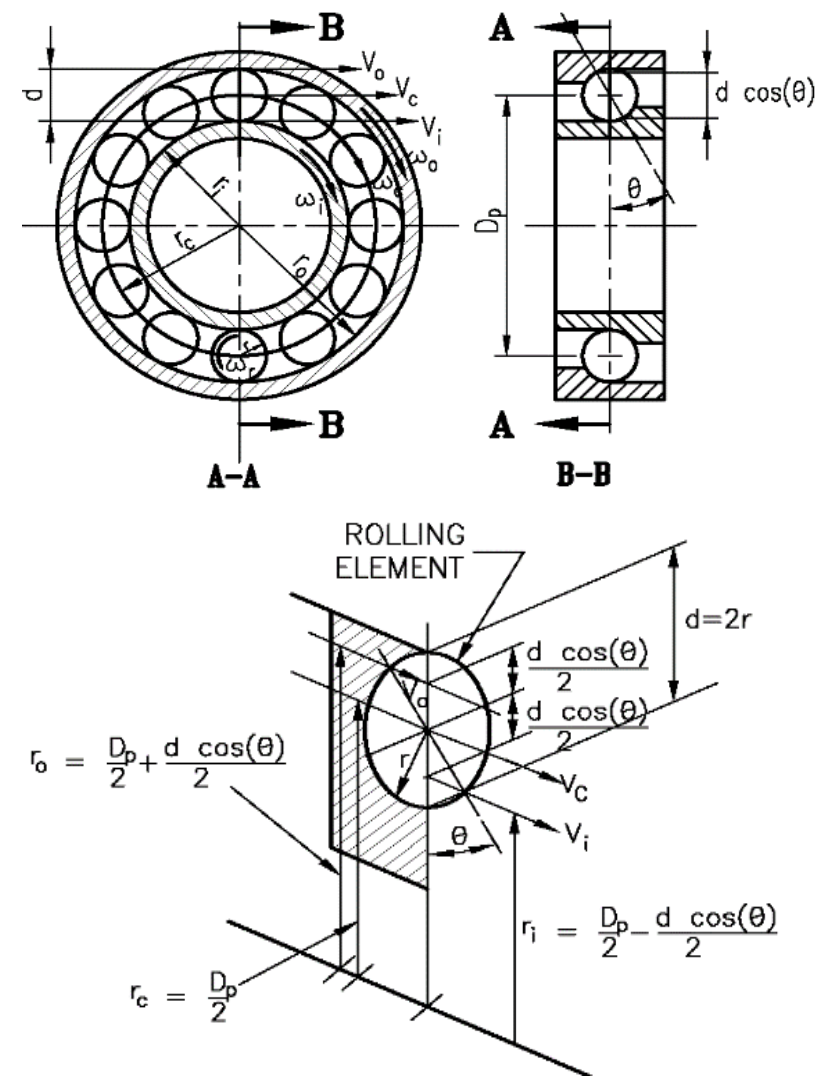

Fig. 6. Schematic diagram of bearing geometry.

Table 2. Defect frequencies.

\begin{tabular}{|c|c|c|c|c|}
\hline \multirow{2}{*}{ RPM } & \multicolumn{4}{|c|}{ Characteristic frequency in Hz } \\
\cline { 2 - 5 } & FTF & BPFO & BPFI & BSF \\
\hline 500 & 3.38 & 40.61 & 59.35 & 21.43 \\
\hline 700 & 4.74 & 56.89 & 83.15 & 30.03 \\
\hline 900 & 6.09 & 73.13 & 106.88 & 38.59 \\
\hline 1100 & 7.45 & 89.36 & 130.60 & 47.16 \\
\hline 1300 & 8.80 & 105.64 & 154.40 & 55.76 \\
\hline 1500 & 10.16 & 121.98 & 178.13 & 64.32 \\
\hline
\end{tabular}

The calculated frequencies of seeded defect rolling element bearings used were given in Table 2. The AE data is processed through FFT with respect to AE lab software. Time waves and frequency spectrums at all test runs are analyzed. The time waves and frequency spectrums of acoustic emission without defect and with defect are presented in Figs. 7 and 8. Similarly, remaining test runs were conducted with different defect sizes with various speeds and load conditions. The peak raised for all frequency spectra is at only one frequency i.e., $B P F O=121.98 \mathrm{~Hz}$ and in the subsequent superharmonics, no other peaks were observed. There are 12 impulses recorded for every 0.1 sec in the expanded time waves which matches with its BPFO. As the peak width increases 
defect size also increases and gives a clear idea about the defect size increment. Consisted AE amplitudes ( $\mathrm{dB}$ level) at defect frequencies for a good bearing and a defective bearing with different defects width $0.3,0.5,0.7,0.9$ and 1.1 $\mathrm{mm}$ at the outer race under $2 \mathrm{kN}$ and $4 \mathrm{kN}$ loads are recorded.

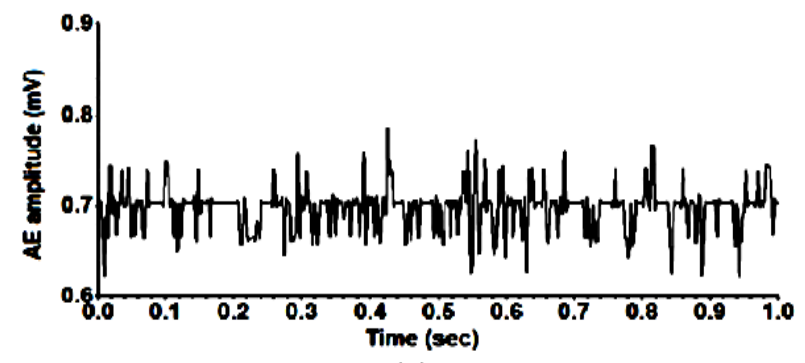

(a)

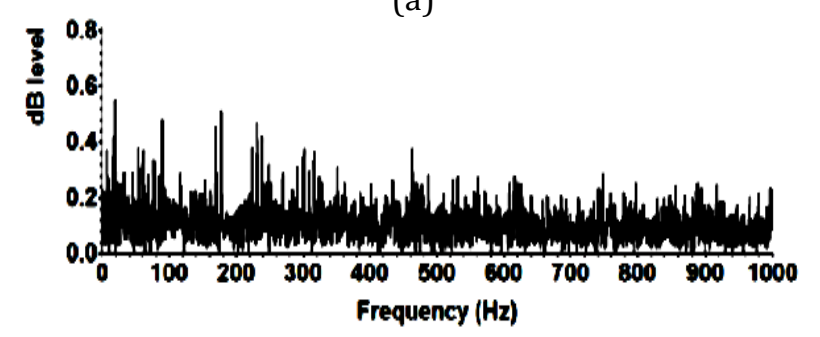

(b)

Fig. 7. AE: (a) time wave, and (b) frequency spectrum of test conditions L2 - N6.

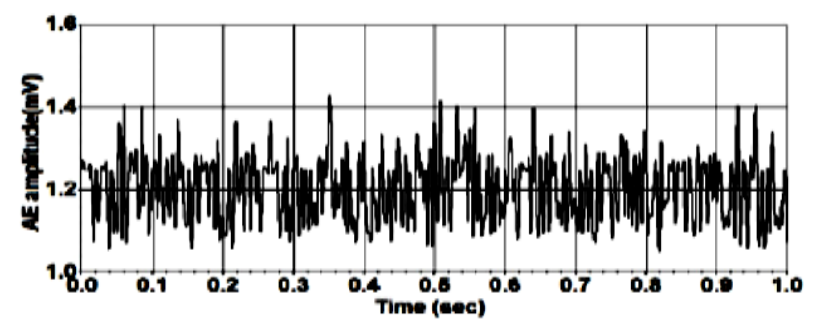

(a)

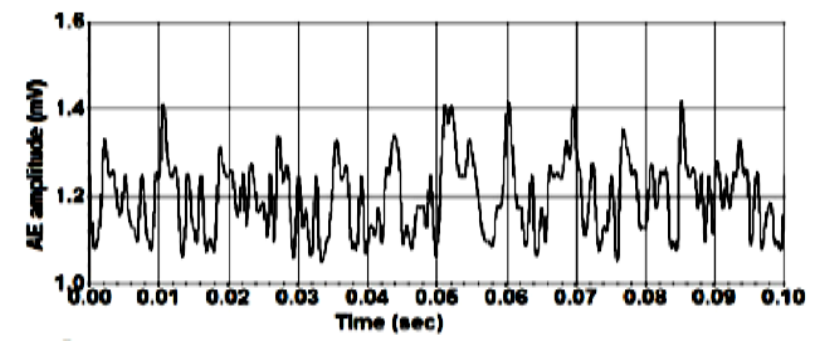

(b)

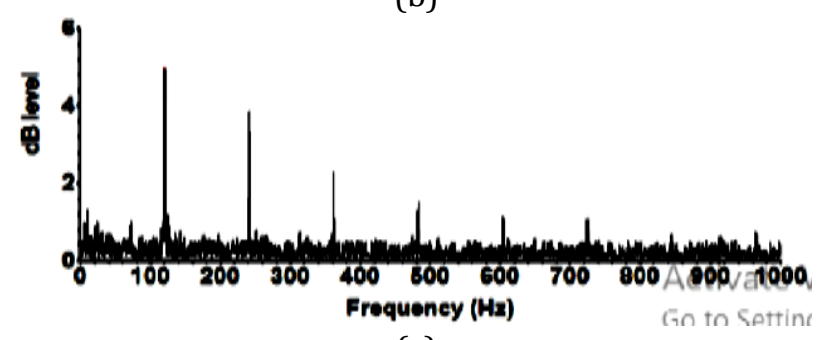

(c)

Fig 8. AE: (a) time wave, (b) enlarged time wave, and (c) frequency spectrum of test conditions L2-D2-N6.
Table 3. Theoretical and actual BPFO in AE spectra.

\begin{tabular}{|c|c|c|c|c|}
\hline \multirow{2}{*}{ RPM } & \multirow{2}{*}{$\begin{array}{c}\text { Theoretical } \\
\text { BPFO }\end{array}$} & \multicolumn{2}{|c|}{ Defect size 0.5 } & \multirow{2}{*}{\begin{tabular}{c} 
Load $2 \mathrm{kN}$ \\
Difference \\
\cline { 3 - 4 }
\end{tabular}} \\
\cline { 3 - 4 } & & $\begin{array}{c}\mathrm{dB} \\
\text { level }\end{array}$ & $\begin{array}{c}\text { Actual } \\
\text { BPFO }\end{array}$ & \\
\hline 500 & 40.61 & 2.04 & 40.404 & 0.106 \\
\hline 700 & 56.89 & 3.43 & 56.608 & 0.282 \\
\hline 900 & 73.13 & 4.32 & 72.224 & 0.906 \\
\hline 1100 & 89.36 & 5.84 & 88.328 & 1.032 \\
\hline 1300 & 105.64 & 4.21 & 104.342 & 1.298 \\
\hline 1500 & 121.98 & 5.07 & 120.536 & 1.344 \\
\hline
\end{tabular}

In Table 3, the theoretical and actual BPFO, at different speeds for a given N312 bearing with $0.5 \mathrm{~mm}$ defect size at $4 \mathrm{kN}$ load, is presented. The tendency was seen in AE analysis and observed as the speed was increasing, the difference of theoretical and actual BPFO increased.

\section{ANN \& SVM TRAINING AND TESTING}

\subsection{STATISTICAL FEATURE}

To recognize the condition of the equipment, features were calculated from the $\mathrm{AE}$ signals. They promote information about the AE signals for diagnosis of REBs. Statistical methods used widely to provide the physical characteristics of frequency domain data [44], extracted were used as a single observation for training and testing of both ANN and SVM.

$$
R M S=\sqrt{1 / N \sum_{n=1}^{N} C_{n}^{2}}
$$

In these relation, $C_{n}, \mathrm{~N}$ are an individual data and sample size respectively.

$$
\begin{gathered}
P_{v}=\frac{1}{2}\left[\max \left(C_{n}\right)-\min \left(C_{n}\right)\right] \\
\text { Crest Factor }=\frac{P_{v}}{R M S} \\
\text { Skewness }=\frac{\frac{1}{N} \sum_{n-1}^{N}\left(C_{n}-\bar{C}\right)^{3}}{R M S^{3}}
\end{gathered}
$$

where $\bar{C}=\mu$ is the mean value.

$$
\begin{gathered}
\text { Kurtosis }=\frac{\frac{1}{N} \sum_{n-1}^{N}\left(C_{n}-\bar{C}\right)^{4}}{R M S^{4}} \\
C l_{f}=\frac{P_{v}}{\left(\frac{1}{N} \sum_{n=1}^{N}\left|C_{n}\right|\right)^{2}}
\end{gathered}
$$

The six time-domain statistical features are RMS, Peak value(Pv), Crest factor (Crf), Skewness (Skew), Kurtosis (Kur), Clearance Factor (CIf) along with $\mathrm{AE}$ amplitude ( $\mathrm{dB}$ level), speeds and loads are used for both ANN and SVM. 


\subsection{TRAINING AND TESTING}

Sixty experiments were planned and for each experiment at least two test runs were conducted. The same AE amplitude ( $\mathrm{dB}$ level) is observed in the two successive test runs. For some experiments, test runs were conducted three to four times to achieve a consistency. A total of 146 test runs were conducted. In the acoustic emission analysis of the damaged bearing, the damage can be detected in its incipient stage, but the defect size cannot be predicted. Hence, ANN and SVM were used to learn the behavior of a specific fault in the bearing and correlate the obtained $\mathrm{AE}$ values with the given parameters to the defect size.

ANN model, as per [45], neural networks is used for predictions and they can identify hidden and strong non-linear dependencies. Network shape was designated by the input data which was divided into three sets training set (learning), validation set and testing set. The default setting of the ratio as per the statistical program is: $70 \%$ of the input data is training set, $15 \%$ validation set and $15 \%$ testing set. To summarize, the training set was used for creating a model, the validation set for verifying the model and the testing set for testing the usability of the model. The Back-propagation network was used to estimate the bearing seeded defect size shown in Fig. 9. The ANN model consists of three layers such as input layers, one hidden layer and output layer respectively. The input layer comprises of nine neurons, such as load, amplitude level, speed, RMS, Peak value, Crest factor, skewness, Kurtosis, Clearance Factor and the one neuron, i.e., defect size was output layer. Through the neurons of hidden layers information from the input was transmitted to the output layer. Use trial and error method for determining neurons in each hidden layer and the number of hidden layers.

Network training/learning is a method of adapting weights with connections between network neurons in each layer. The training of the network was done with back propagation algorithm shown in Fig. 10. The orange lines, red line, green line, and blue line, shown in graph signify validating error (Ave), maximum example error, average example error and minimum example error respectively shown in
Fig. 10. A plot was constructed between learning cycles on $\mathrm{X}$ axis and target error on the $\mathrm{Y}$ axis. Samples of 53 used for training ANN and 6 for validation. If average training error and the target error which were set to 0.001 spontaneously learning process has stopped at 25,000 cycles. As shown in the Fig. 10, the green lines, blue line, yellow lines were found to be below target error. The learning rate was 0.6 and the momentum was 0.8 for the trained network. The software Easy NN-plus version 8.0 [46] was introduced here to design the ANN model and it has the capacity of carry 90 connection weights in between input layers and hidden layer, 10 in between hidden layer and output layer.

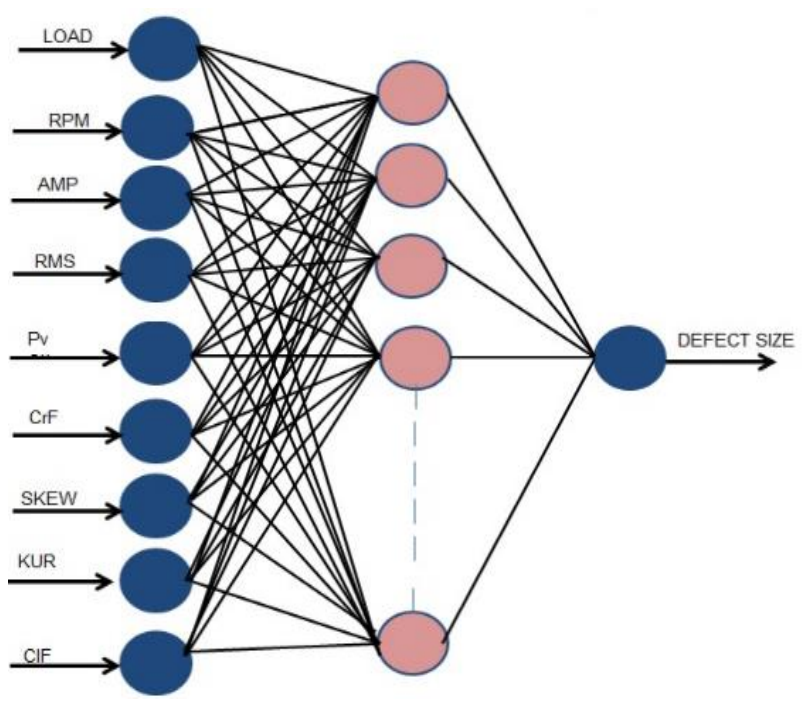

Fig 9. ANN topology (9-10-1).

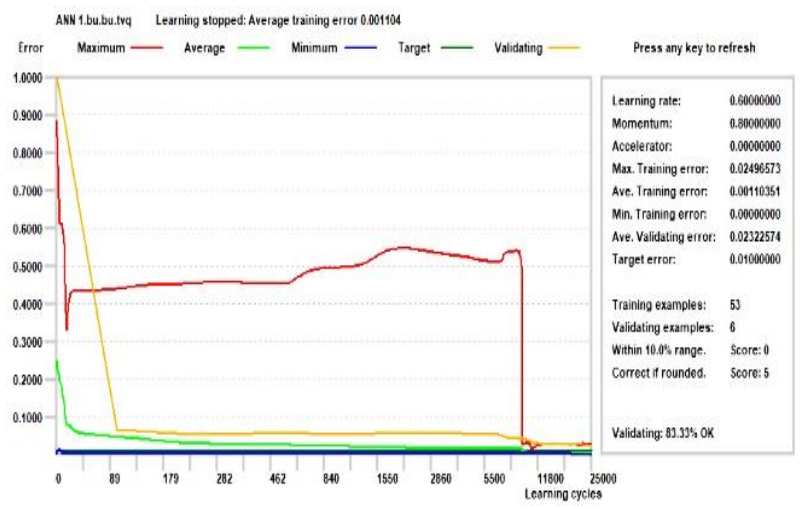

Fig. 10. Learning progress graph with maximum, average and minimum training error.

SVM model is used to predict the seeded fault size and compared with the experimental data. Rapid miner 5.0 software developed for SVM model. A nonlinear kernel was preferred rather than using linear kernel for its better 
performance [29]. Then dot function kernel was selected. SVM coefficients are C and $\varepsilon$ and its values are 1000 and 0.001 for seeded defect size shown in Fig. 11. Basic pairs of $C$ and $\varepsilon$ are tried and select the best cross-validation. After frequent tests, coefficients $C$ and $\varepsilon$ are selected as 1,000 and 0.001 for Defect size-SVM model.

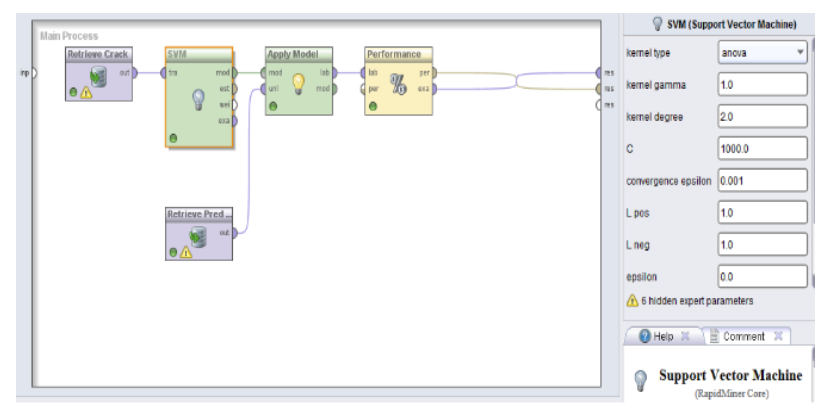

Fig 11. Rapid Miner 5.3 S/w for SVM model.

Then the SVM is trained using training data. This Rapid miner 5.0 software has been used here for the application of SVM in predicting the defect size of the test bearings. The training sets $\mathrm{X}$ is the combined vector of all the nine input parameters such as speed, load, amplitude level, RMS, Peak value, Crest factor, skewness, Kurtosis, Clearance Factor and the training set $Y$ is one yield parameter i.e., defect size.

\section{RESULTS}

In this work testing involves mounting the bearing with different sizes of seeded defects in the test bearing house and run this with different load conditions and at various speeds. $\mathrm{AE}$ data acquisition is done at each test run. Here, NTN N312 type cylindrical roller bearing is used as test bearing. It has an advantage of easy assembly and dismantling of outer race, so that the creation of artificial defect in outer race becomes easy. Wire Cut EDM (Electro Discharge Machining) is a non-conventional machining process used for creating defects in outer race. Five bearings of the NTN N312 type used and defects were created in the outer races of varying width sizes i.e., $0.3,0.5,0.7,0.9$ and 1.1 $\mathrm{mm}$ with the same depth of defect i.e., 0.3 for all five bearing.

Wire Cut EDM (Electro Discharge Machining) is a non-conventional machining process used for creating defects in outer race. Five bearings of the NTN N312 type used and defects were created in the outer races of varying width sizes i.e., $0.3,0.5,0.7,0.9$ and $1.1 \mathrm{~mm}$ with the same depth of defect i.e., 0.3 for all five bearing. The test shaft and the test bearing house were used to assemble healthy bearing and defect bearings. $\mathrm{AE}$ sensors were placed on the house of test bearing. By controlling the required speeds from 500 to 1500 and loads i.e., $2 \mathrm{kN}$ and $4 \mathrm{kN}$ respectively. $\mathrm{AE}$ time wave signal data file recorded by the $\mathrm{AE}$ instrument and processed using $\mathrm{AE}$ lab software provided with the instrument. Time waves and frequency spectrums for all test runs were analyzed. Some of them shown in Figs. 7 and 8. AE amplitudes $(\mathrm{dB})$ at various defect sizes, speeds and loads were computed. The six time-domain statistical features are RMS, Peak value (Pv), Crest factor (Crf), Skewness (Skew), Kurtosis (Kur), Clearance Factor (CIf) along with AE amplitude (dB level), speeds and loads are used for both ANN and SVM.

Sixty different experiments are planned and for each experiment two test runs were conducted to achieve consistency of results total 146 test runs conducted. Input-output pairs were used for training of the ANN and SVM model. After training the models, the final prediction models for output objectives are obtained. The five groups of testing data are used to test the models. The comparison results between the actual seeded defect size and the predicted values of the defect size using ANN and SVM are shown in Table 6 . The calculation of percentage error between the actual defect size and its predicted size using ANN and SVM shows an average defect size error of $6.57 \%$ and $6.90 \%$ respectively as shown in Table 7 . Figure 12 shows a graph of comparison between the actual and the predicted defect sizes of testing data using both models.

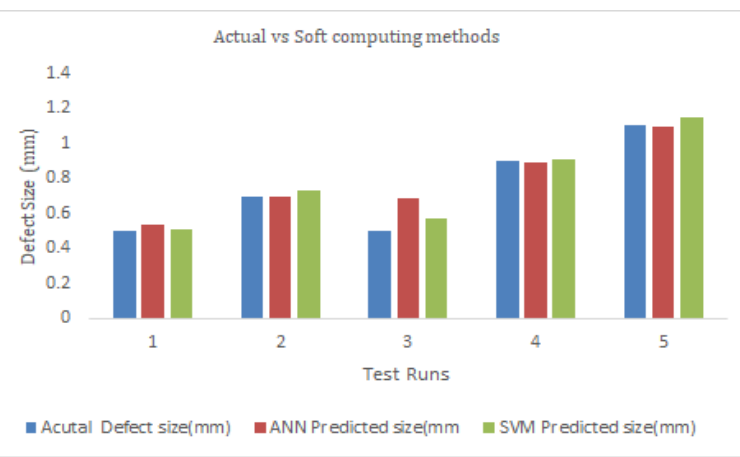

Fig 12. Defect size comparison with actual versus Soft computing methods predicted values. 
Table 6. Test results of ANN \& SVM.

\begin{tabular}{|c|c|c|c|c|c|c|c|c|c|c|c|c|}
\hline \multirow{2}{\text{S.}}{$\begin{array}{c}\text { Noad } \\
\text { (KN) }\end{array}$} & RPM & $\begin{array}{c}\text { Amplitude } \\
\text { (dB level) }\end{array}$ & rms & $\begin{array}{c}\text { Peak } \\
\text { value }\end{array}$ & $\begin{array}{c}\text { Crest } \\
\text { Factor }\end{array}$ & Skewness & Kurtosis & $\begin{array}{c}\text { Cl } \\
\text { factor }\end{array}$ & $\begin{array}{c}\text { Seeded } \\
\text { defect size } \\
\text { (mm) }\end{array}$ & \multicolumn{2}{c|}{$\begin{array}{c}\text { Predicted } \\
\text { defect size } \\
\text { (mm) }\end{array}$} \\
\hline 1 & 2 & 500 & 1.8 & 0.89 & 0.27 & 0.33 & 0.0004 & 0.0001 & 0.05 & $\mathbf{0 . 5}$ & $\mathbf{0 . 5 3 4 3}$ & $\mathbf{0 . 5 0 6}$ \\
\hline 2 & 2 & 900 & 3.75 & 0.99 & 0.27 & 0.28 & 0.0007 & 0.0002 & 0.08 & $\mathbf{0 . 7}$ & $\mathbf{0 . 6 9 6 7}$ & $\mathbf{0 . 7 3}$ \\
\hline 3 & 4 & 900 & 4.32 & 0.95 & 0.23 & 0.25 & 0.0005 & 0.0002 & 0.07 & $\mathbf{0 . 5}$ & $\mathbf{0 . 6 8 4 6}$ & $\mathbf{0 . 5 7}$ \\
\hline 4 & 4 & 500 & 3.04 & 0.84 & 0.3 & 0.36 & 0.0004 & 0.0002 & 0.07 & $\mathbf{0 . 9}$ & $\mathbf{0 . 8 9 4 2}$ & $\mathbf{0 . 9 1 1}$ \\
\hline 5 & 4 & 1500 & 11.8 & 1.26 & 0.31 & 0.25 & 0.0009 & 0.0003 & 0.13 & $\mathbf{1 . 1}$ & $\mathbf{1 . 0 9 9 9}$ & $\mathbf{1 . 1 5}$ \\
\hline
\end{tabular}

Table 7. Average defect size error in both ANN \& SVM.

\begin{tabular}{|c|c|c|c|c|c|c|c|}
\hline \multirow{2}{*}{ S. No } & \multirow{2}{*}{$\begin{array}{c}\text { Load } \\
\text { (KN) }\end{array}$} & RPM & \multirow{2}{*}{$\begin{array}{c}\text { Seeded } \\
\text { defect size } \\
\mathbf{( m m )}\end{array}$} & $\begin{array}{c}\text { Predicted } \\
\text { defect size } \\
(\mathrm{mm})\end{array}$ & $\begin{array}{c}\text { Error } \\
\%\end{array}$ & $\begin{array}{c}\text { Predicted } \\
\text { defect size } \\
(\mathrm{mm})\end{array}$ & $\begin{array}{c}\text { Error } \\
\%\end{array}$ \\
\hline 1 & 2 & 500 & 0.5 & 0.5343 & 6.42 & 0.506 & 1.19 \\
\hline 2 & 2 & 900 & 0.7 & 0.6967 & 0.47 & 0.73 & 4.11 \\
\hline 3 & 4 & 900 & 0.5 & 0.6846 & 26.96 & 0.57 & 12.28 \\
\hline 4 & 4 & 500 & 0.9 & 0.8942 & 0.64 & 0.911 & 1.21 \\
\hline 5 & 4 & 1500 & 1.1 & 1.0999 & 0.01 & 1.15 & 14.09 \\
\hline \multicolumn{3}{|c|}{ Average of \% error } \\
\hline
\end{tabular}

\section{CONCLUSION}

The experiments were carried out on Rolling Element Bearings, to estimate the defect size with six levels of speed, five levels of defect size and two levels of load. AE time wave signals acquired with an $\mathrm{AE}$ probe were analyzed through FFT with AE lab software. As the peak width of $\mathrm{AE}$ amplitude increases defect size also increases and gives a clear idea about the defect size increment. Consisted AE amplitudes (dB level) at defect frequencies for a good bearing and a defective bearing with five different speeds, such as 500, 700, 900, 1100, 1500 (rpm's), different defects width $0.3,0.5,0.7,0.9$ and $1.1 \mathrm{~mm}$ at outer race under two loads as 2 $\mathrm{kN}, 4 \mathrm{kN}$ were recorded.

In the acoustic emission analysis, the damage in the outer race can be detected in its incipient stage and the defect size can be predicted by ANN \& SVM model. The time domain statistical features such as Kurtosis, RMS, Crest factor, Peak value, skewness, Clearance Factor along with AE amplitude (dB level), speeds and loads were used for prediction of defect size using ANN \& SVM. Easy NN plus software was used to create the neural network (9-10-1) was developed to predict the defect size. This Rapid miner 5.0 software has been used here for the application of SVM in predicting the defect size of the test bearings. It was observed that there was a near relation between experimental data and predicted values of seeds defect size for both (6.90 \% for ANN, $6.57 \%$ of error for SVM).

\section{REFERENCES}

[1] C. Senthilraja, L. Vinoth, A Review on Fault Diagnosis of Ball Bearing Using Sound and Vibration Signals, International Journal of Innovative Research in Science, Engineering and Technology, vol. 4, iss. 13, pp. 381-393, 2015.

[2] H. Patidar, Study of detection of defects in rolling element bearings using vibration and acoustic measurement methods - A Review, International Journal of Mechanical Engineering Research \& Technology, vol. 1, no. 1, pp. 1-15, 2015.

[3] V.V. Rao, Ch. Ratnam, A Comparative Experimental Study on Identification of Defect Severity in Rolling Element Bearings using Acoustic Emission and Vibration Analysis, Tribology in Industry, vol. 37, no. 2, pp. 176185, 2015.

[4] M. Cerrada, R.-V. Sanchez, C. Li, R.E. Vasquez, Review - A review on data-driven fault severity assessment in rolling bearings, Mechanical Systems and Signal Processing, vol. 99, pp. 169-196, 2018, doi: 10.1016/i.ymssp.2017.06.012

[5] B.A. El Anouar, M. Elamrani, B. Elkihel, F. Delaunois, I. Manssouri, A comparative experimental study of different methods in detection and monitoring bearing defects, 
International Journal of Advanced Scientific and Technical Research, vol. 1, iss. 7, pp. 409423, 2017.

[6] A. Cockerill, A. Clarke, R. Pullin, T. Bradshaw, P. Cole, K.M. Holford, Determination of rolling element bearing condition via acoustic emission, Proceedings of the Institution of Mechanical Engineers, Part J: Journal of Engineering Tribology, vol. 230, iss. 11, pp. 1377-1388, 2016, doi: 10.1177/1350650116638612

[7] W. Caesarendra, B. Kosasih, A.K. Tieu, H. Zhu, C.A.S. Moodie, Q. Zhu, Acoustic emission-based condition monitoring methods: Review and application for low speed slew bearing, Mechanical Systems and Signal Processing vol. 72-73, pp. 134-159, 2016, doi: 10.1016/j.ymssp.2015.10.020

[8] F. Hekmati, M. Alqaradawi, M.S. Gadala, Rolling element bearing fault diagnostics using acoustic emission technique and advanced signal processing, Proceedings of the Institution of Mechanical Engineers, Part J: Journal of Engineering Tribology, vol. 230, iss. 1, pp. 6477, 2015, doi: $10.1177 / 1350650115591233$

[9] J.L.F. Chacon, V. Kappatos, W. Balachandran, T.H. Gan, A novel approach for incipient defect detection in rolling bearings using acoustic emission technique, Applied Acoustics vol. 89, pp. 88-100, 2015, doi: 10.1016/j.apacoust.2014.09.002

[10] M. Entezami, E. Stewart, J. Tutcher, W. Driscoll, R. Ellis, G. Yeo, Z. Zhang, C. Roberts, T. Kono, S. Bayram, Acoustic Analysis Techniques for Condition Monitoring of Roller Bearings, 6th IET Conference on Railway Condition Monitoring (RCM 2014), 17-18 Sept., Birmingham, UK, 2014, pp. 1-8, doi: $10.1049 /$ cp.2014.1012

[11] S.M.A. Al-Obaidi, M. Salman Leong, R.I. Raja Hamzah, Ahmed M. Abdelrhman, A Review of Acoustic Emission Technique for Machinery Condition Monitoring: Defects Detection \& Diagnostic, Applied Mechanics and Materials vol. 229-231, pp. 1476-1480, 2012, doi: 10.4028/www.scientific.net/AMM.229231.1476

[12] S. Pimentel Junior, Acoustic Emission Tests on the Analysis of Cracked Shafts of Different Crack Depths, 23rd ABCM International Congress of Mechanical Engineering, vol. 6-11, 2015.

[13] D.S. Gu, J.G. kim, Y.S. An, B.K. Choi, Detection of faults in gearboxes using acoustic emission signal, Journal of Mechanical Science and Technology, vol. 25, pp. 1279-1286, 2011, doi: 10.1007/s12206-011-0231-4
[14] L. Batista, B. Badri, R. Sabourin, M. Thomas, Detecting bearing defects under high noise levels: a classifier fusion approach, In: Proceedings of IECON, 38th annual conference on IEEE industrial electronics society, Montreal, pp. 3880-3886, 2012, doi: 10.1109/IECON.2012.6389272

[15] M.J. Nerella, Ch. Ratnam, V.V. Rao, Study of Detection of Defects in Rolling Element Bearings Using Acoustic Measurement Methods - A Review, SSRG International Journal of Mechanical Engineering (SSRG-IJME), iss. 5, pp. 110-116, 2017.

[16] M. Kedadouche, M. Thomas, A. Tahan, Cyclostationarity applied to acoustic emission and development of a new indicator for monitoring bearing defects, Mechanics \& Industry, vol. 15, iss. 6, pp. 467-476, 2014, doi: $10.1051 /$ meca $/ 2014061$

[17] M.S. Othman, M.Z. Nuawi, R. Mohamed, Vibration and Acoustic Emission Signal Monitoring for Detection of Induction Motor Bearing Fault, International Journal of Engineering Research \& Technology (IJERT), vol. 4, iss. 5, pp. 924-929, 2015.

[18] B. Badri, A shock filter for bearing slipping detection and multiple damage diagnosis, International Journal of Mechanics, vol. 5, iss. 4, 2011.

[19] M. Kedadouche, M. Thomas, Tahan, A Monitoring bearing by acoustic emission: a comparative study with vibration techniques for early detection. In: Proceedings of the 30th seminar on machinery vibration, CMVA, Niagara Falls, Canada, pp. 17, 2012.

[20] J. Patel, A. Patel, V. Patel, Fault Diagnostics of Rolling Bearing based on Improve Time and Frequency Domain Features using Artificial Neural Networks, International Journal for Scientific Research \& Development, vol. 1, iss. 4, pp. 816-823, 2013.

[21] S. Hosseini, A. Al Khaled, A survey on the imperialist competitive algorithm metaheuristic: Implementation in engineering domain and directions for future research, Applied Soft Computing, vol. 24, pp. 10781094, 2014, doi: 10.1016/j.asoc.2014.08.024

[22] M. Kishan, K.M. Chilukuri, R. Sanjay, Elements of artificial neural networks, Cambridge: The MIT Press, 1997.

[23] K. Ramesh, Investigation of chatter stability in boring tool and tool wear prediction using neural network, International Journal of Materials and Product Technology, vol. 46, iss. 1, pp. 47-70, 2013, doi: 10.1504/IJMPT.2013.052789 
[24] R.A. Kanai, R.G. Desavale, S.P. Chavan, Experimental-Based Fault Diagnosis of Rolling Bearings Using Artificial Neural Network, Journal of Tribology, ASME, vol. 138, iss. 3, p. 9, 2016, doi: 10.1115/1.4032525

[25] D.H. Pandya, S.H. Upadhyay, S.P. Harsha, ANN based fault diagnosis of rolling element bearing using time-frequency domain feature, International Journal of Engineering Science and Technology, vol. 4, no. 6, pp. 2878-2886, 2012.

[26] V.V. Rao, C. Ratnam, Estimation of Defect Severity in Rolling Element Bearings using Vibration Signals with Artificial Neural Network, Jordan Journal of Mechanical and Industrial Engineering, vol. 9, no. 2, pp. 113$120,2015$.

[27] M.J. Nerella, Ch. Ratnam, Fault Diagnosis of a Rolling Element Bearings Using Acoustic Condition Monitoring and Artificial Neural Network Technique, International Research Journal of Engineering and Technology (IRJET), vol. 5, iss. 3, 2018.

[28] V.N. Vapnik, Statistical learning theory, IEEE Transactions on Neural Networks, John Wiley \& Sons, New York, 1998.

[29] K.V. Rao, P.B.G.S.N. Murthy, Modeling and optimization of tool vibration and surface roughness in boring of steel using RSM, ANN and $S V M$, Journal of Intelligent Manufacturing, pp. 1-11, 2016, doi: 10.1007/s10845-016-1197-y

[30] A.K. Gupta, Predictive modelling of turning operations using response surface methodology, artificial neural networks and support vector regression, International Journal of Production Research, vol. 48, iss. 3, pp. 763-778, 2010, doi: 10.1080/00207540802452132

[31] S.E. Pandarakone, K. Akahori, T. Matsumura, Y. Mizuno, H. Nakamura, Development of a methodology for bearing fault scrutiny and diagnosis using SVM, 2017 IEEE International Conference on Industrial Technology (ICIT), Toronto, ON, 2017, pp. 282-287, doi: 10.1109/ICIT.2017.7913097

[32] D.D. Susilo, A. Widodo, T. Prahasto, M. Nizam, Fault Diagnosis of Roller Bearing Using Parameter Evaluation Technique and MultiClass Support Vector Machine, AIP Conference Proceedings, 2017, doi: 10.1063/1.4968334

[33] S.M. Ali, K.H. Hui, L.M. Hee, M.S. Leong, Automated valve fault detection based on acoustic emission parameters and support vector machine, Alexandria Engineering, vol. 57, iss. 1, pp. 491-498, 2018, doi: 10.1016/j.aej.2016.12.010
[34] S.U. Jan, Y.-D. Lee, J. Shin, I. Koo, Sensor Fault Classification Based on Support Vector Machine and Statistical Time-Domain Features, IEEE Access, vol. 5, pp. 8682-8690, 2017, doi: 10.1109/ACCESS.2017.2705644

[35] T. Praveenkumar, M. Saimurugan, P. Krishnakumar, K.I. Ramachandra, Fault diagnosis of automobile gearbox based on machine learning Technique, Procedia Engineering, vol. 97, pp. 2092 - 2098, 2014, doi: 10.1016/j.proeng.2014.12.452

[36] N.M. Jasmin, Ch. Ratnam, V.V. Rao, K.V. Rao, Bearing Defect Size Estimation Based on Support Vector Machine and Acoustic Emission Signals, International Journal of Advance Engineering and Research development, vol. 5, iss. 4, pp. 431-442, 2018.

[37] Y.-W. Hsueh, C.-Y. Yang, Prediction of tool breakage in face milling using support vector machine, The International Journal of Advanced Manufacturing Technology, vol. 37, iss. 9-10, pp. 872-880, 2008, doi: 10.1007/s00170-007-1034-8

[38] B. Samanta, Gear fault detection using artificial neural networks and support vector machines with genetic algorithms, Mechanical Systems and Signal Processing, vol. 18, iss. 3, pp. 625-644, 2004, doi: 10.1016/S0888-3270(03)00020-7

[39] P.K. Kankar, S.C. Sharma, S.P. Harsha, Fault diagnosis of ball bearings using machine learning methods, Expert Systems with Applications, vol. 38, iss. 3, pp. 1876-1886, 2011, doi: 10.1016/j.eswa.2010.07.119

[40] J.P. Patel, S.H. Upadhyay, Comparison between Artificial Neural Network and Support Vector Method for a Fault Diagnostics in Rolling Element Bearings, Procedia Engineering, vol. 144, pp. 390-397, 2016, doi: 10.1016/j.proeng.2016.05.148

[41] S. Tyagi, DWT and SVM based method for rolling element bearing fault diagnosis and its comparison with Artificial Neural Network, Journal of Applied and Computational Mechanics, vol. 3, no. 1, pp. 80-91, 2017, doi: 10.22055/jacm.2017.21576.1108

[42] G.S. Vijay, P.S. Pai, N.S. Sriram, Comparative Study of Soft Computing Techniques for Rolling Element Bearing Condition Monitoring using Vibration Signal Analysis, Conference or Workshop Item, 25 Mar 2013.

[43] S. Singh, N. Kumar, Rotor Faults Diagnosis Using Artificial Neural Networks and Support Vector Machines, International Journal of Acoustics and Vibration, vol. 20, no. 3, pp. 153-159, 2015. 
[44] M.R. Asadi, Fault diagnosis of a differential using Acoustic condition monitoring and Artificial neural network technique, Journal of current research in science, vol. 1, no. 6, pp. 575-582, 2013.

[45] 0. Krejcar, Utilization of C\# Neural Networks Library in Industry Applications. In: Yonazi J.J., Sedoyeka E., Ariwa E., El-Qawasmeh E. (eds) e-
Technologies and Networks for Development. ICeND 2011. Communications in Computer and Information Science, vol. 171. Springer, Berlin, Heidelberg, 2011.

[46] EasyNN-plus, Version 8.0, Neural Planner Software Ltd, England, UK. Available at: http://www.easynn.com 